\title{
5 INFORMATION SYSTEMS CONCEPTUAL FOUNDATIONS: LOOKING BACKWARD AND FORWARD
}

\author{
Gordon B. Davis \\ University of Minnesota \\ U.S.A.
}

\begin{abstract}
The academic field of information systems has developed because organizations use a specialized body of knowledge about information and communications systems. Teaching and research support these organization needs. The field may be defined in terms of observed information systems in organizations and also in terms of the function or field of activity for system planning, development, management, and evaluation. Since the systems deal with capture, repositories, processing, and communication of data, information, and knowledge, these are also defined.

Conceptual foundations for the field are the set of concepts and propositions that explain why structures are designed the way they are, tasks are scheduled and accomplished in the way they are, and activities are performed the way they are. There are three approaches to conceptual foundations: an intersection approach that accepts any concept from any field if it appears to add insight and explanation to information systems practice and research, a core approach that seeks to define those ideas that characterize the discipline and make it distinct, and an evolutionary approach that seeks a cohesive set of concepts by combining the concepts from the core approach with concepts from other fields that over time are found to be especially useful to information systems.

At this time, there is significant variety and a number of concepts that are said to be useful in research and practice. In the long run,
\end{abstract}

The original version of this chapter was revised: The copyright line was incorrect. This has been corrected. The Erratum to this chapter is available at DOI: 10.1007/978-0-387-35505-4_33 
the evolutionary approach relative to conceptual foundations will probably prevail and reduce the scope and variety somewhat. It is a mixed strategy that fits the diversity inherent in a worldwide community of scholars. As the core concepts are developed and clarified, the core will be strengthened. However, there will still continue to be strong use of other bodies of knowledge containing concepts that support explanation and research relative to information systems.

\section{Introduction}

For both academic and research purposes, the field of information systems deals with systems for delivering information and communications services in an organization and the activities and management of the information systems function in planning, designing, developing, implementing, and operating the systems and providing services. These systems capture, store, process, and communicate data, information, and knowledge. The systems combine both technical components and human operators and users. The environment is an organization or a combination of organizations. Participants tend to describe the organization in terms of purposive, goal directed behavior, but in practice the organization also reflects personal agendas, power issues, prejudices, misunderstandings, etc. To explain this combination of technology, human participants, rationality, and other behaviors requires a rich set of concepts.

Starting in the 1960s and 1970s, research in information systems looked to bodies of knowledge that contained concepts and research results or research methods relevant to the study of information systems and the activities of information systems personnel. The bodies of knowledge most often used were system concepts (both soft and hard), information concepts, humans as information processors, organization behavior, management, and decision making.

The body of concepts (the conceptual foundations) has grown, and subspecialties are emerging. The paper explores three views relative to the growth of conceptual foundations. The first is an open view, that the intersection of disciplines provides rich opportunities and, therefore, the growth should be tolerated and perhaps encouraged. The second view is that this growth leads to a chaotic field that has difficulty coexisting with fields that have drawn tight boundaries around their disciplines. The proponents of the second view propose an emphasis on the essential core, that which differentiates information systems from other disciplines. The third, the evolutionary view, believes that the field will be somewhat more bounded because many conceptual foundations are not sufficiently robust relative to information systems to maintain themselves as part of the field. In other words, the field will naturally begin to be more selective. This view encourages more emphasis on the core but resists excluding bodies of knowledge that enrich the explanations of the field.

The paper presents some assumptions about the field of information systems, develops a definition of the field, describes three approaches to conceptual foundations, describes the current situation relative to conceptual foundations, and presents the author's view of future development of conceptual foundations for the field and its effect on research. 


\section{Some Assumptions about the Field of Information Systems}

The paper rests on some assumptions about the nature of the field of information systems (by whatever name), the field being applied rather than basic science, the necessary practitioner connection, the nature of organizations employing information systems, and the complementary rather than alternative nature of different views of information systems. Although the field theoretically may develop a research agenda and conceptual foundations separate from its education mission, there is likely to be interaction.

\subsection{A Field by Whatever Name}

In North America, the terms information system (IS) and management information system (MIS) are identical in meaning and interchangeable in use. They refer to the system providing information technology-based information and communication services in an organization. These terms, and similar terms such as information management, also refer to the organization function that manages the system. The system terms and function names are broad in scope and encompass information technology systems and applications for transactions and operations, support of administrative and management functions, organizational communications and coordination, and for adding value to products and services. The academic field may be termed information systems (or IS), management information systems (MIS), information management, or management of information systems (MoIS). In other countries, there may be variations, such as informatics (often modified by organization, administration, or a similar term to differentiate from informatics as computer science).

The changes in terminology in the field reflect changes in the scope and consequently the research agenda. When computers were first utilized in organizations in the mid$1950 \mathrm{~s}$, the applications were primarily simple processing of transaction records and preparation of business documents and standard reports. This use was termed data processing (DP) or electronic data processing (EDP). The business function for developing and managing the processing systems was also termed data processing. By the mid-1960s, many users and builders of information processing systems developed a more comprehensive vision of what computers could do for organizations. This vision was termed a management information system (MIS). It enlarged the scope of data processing to add systems for supporting management and administrative activities including planning, scheduling, analysis, and decision making. The business function to build and manage the management information system was often termed MIS.

In the 1980s and 1990s, there was a merging of computer and communications technologies in organizations. The organizational use of information technology was extended to internal and external networks, systems that connect an organization to its suppliers and customers, and communications systems that enablepeople in organizations to perform work alone or in groups with greater effectiveness and efficiency. Many organizations were able to achieve competitive advantage by the use of information and information technology in products, services, and business processes. Innovative 
applications based on information technology created value by providing services any time, at any location, and with extensive customization. Web-based communication and transaction applications became common. Information technology-based systems were employed to change organization structures and processes. There emerged a tendency to employ simple, general terms such as information systems or information management to identify both the multifaceted information technology systems and the corresponding organization function.

\subsection{Information Systems as an Applied Academic Field Must Connect to Practice}

Information systems is a relatively new organization function and academic field. Although there have been some changes in other business functions and related academic fields, the set of organization functions has remained reasonably stable since the advent of modern management and organization theory and practice. What then is the basis for a new function and a new academic field?

Organizations have separate functions because of the benefits of specialization and the limits of humans in dealing with specialized bodies of knowledge and practice. There is a separate marketing function because there is a specialized body of marketing knowledge and specialized marketing activities that are performed best by specialists. The entire organization needs some understanding of marketing, accounting, finance, etc., but not everyone can be expected to have sufficient depth of knowledge and skill to perform all activities. Using accounting as an example, everyone uses accounting reports and provides input into accounting, but end-user accounting in which each person decided on the chart of accounts to use and the rules and procedures for accounts and reports would result in confusion and lack of performance of vital functions. The accounting function has specialists who deal with the chart of accounts, financial reporting, reports to governments and regulators, analysis of financial results, etc.

Information systems emerged as a separate organization function because of the need for specialized development and operational activities and specialized management procedures. It is possible to outsource many technical activities, but the core activities of strategic planning for information systems, determining requirements, obtaining and implementing systems, providing support, evaluation, and so forth require technical and managerial specialists.

Academic fields emerge when there is a body of specialized knowledge and practice that can be provided by an academic discipline. There is a strong mapping of organizational and societal needs to the fields of study in colleges and universities. The observed systems and activities of organization functions provide the basis for research. This logic is demonstrated in the development of the academic field of information systems.

There is a direct relationship between the activities of the information systems function in an organization and the academic field of information systems. The academic field describes the structure and activities of the function and explains "why" they are needed, "why" they are organized and conducted the way they are, and alternatives that may be applied and conditions suggesting their use. The academic body of knowledge not only describes and explains but also guides the development and application of practice by suggesting concept-based improvements. The rationale for the explanations, 
suggestions, and alternatives are derived from concepts and theories of human organization, communications, decision making, human capabilities, and so forth. The concepts employed are selected from large bodies of underlying discipline knowledge; selection is based on relevance to explaining or guiding practice. The debate over research rigor versus relevance to practice is ongoing. A recent issue of the MIS Quarterly (Vol. 23, No 1, March 1999) presented many facets of this debate with responses from well-known scholars. The issue also contained articles on qualitative, interpretive, and case research in information systems.

\begin{tabular}{|c|}
\hline Information systems in organizations \\
IS practice \\
$\downarrow$ \\
Academic body of knowledge describing, \\
explaining, and guiding IS practice \\
Includes concepts developed especially for IS \\
or appropriated and specialized for information systems \\
(body of information systems theory) \\
$\downarrow$ \\
Relevant selections from bodies of \\
underlying discipline knowledge
\end{tabular}

\section{Figure 1. Relationship of Practice to Field Theory to Underlying Disciplines}

\subsection{Information Systems Support Organization Objectives and Organizational Rationality}

It is clear that the normative view of organizations as having clear objectives, pursuing these objectives with rationality, and employing information system to support analytical processes is not a complete picture of how organizations operate in practice. However, this normative view (typified by Simon) is a useful presumption. It supports the design of an information system meeting ideal requirements. Since organizations never function according to the ideal, why design for it? Because it provides a coherent model of organizations and information systems. A view that organizations are chaotic in nature and irrational in operation provides an unstable basis for development and implementation of systems.

\subsection{Complementary Nature of Different Views of Information Systems}

The orderly, rational view of organizations provides the basic model and basic assumptions for the design and development of information systems. Alternative views provide a basis for adjustments to processes and procedures in order to deal with organizations 
as they are. A view of information systems research (see Boland and Hirschheim 1987; Cotterman and Senn 1992; Nissen, Klein, and Hirschheim 1991) suggests the scope of these alternatives. They enlarge the ability of analysts and users to improve design and use of systems. Two examples are a socio-technical perspective and a human-centered perspective. The socio-technical perspective is described in a number of publications, especially by Mumford. I have used Nurminen's humanistic perspective as the basis for a human-centered view (Nurminen 1988).

The socio-technical perspective does not reject the idea of rationality in organizations and the existence of organizational objectives to be met. The perspective emphasizes the fact that technology affects the nature of work, and there are alternative ways to incorporate technology into work design. Those who are affected by the introduction of technology should be included in the design process. The final design reflects the social nature of work as well as the efficient use of technology. The socio-technical perspective complements the technical systems perspective.

In the rational, technical perspective, tasks are performed by dividing functions and activities between humans and technology. Humans are assigned functions and activities requiring the unique abilities of humans; computers and other information technology perform functions and activities to which they are suited. To the designer, humans and machines are alternative objects to be designed into the system. An alternative perspective is to view humans as being able to construct work activities using tools provided to them. The emphasis of the designer is to provide a set of information technology functions that a human user can employ in performing a task. Again, the underlying assumption of organizations with purpose and rationality is not eliminated. The rational process of combining capabilities of humans and machines is the starting point for thinking about the design of a system. The human-centered view complements the technical view by introducing the notion that improvement in organizational systems can be achieved if humans are given tools to support self-design of activities to accomplish tasks.

\subsection{A Teaching Perspective on Different Views}

There are teaching implications to how academics formulate the field and deal with its complexity. Those who teach information systems across the spectrum from beginning survey courses for all students to advanced courses for majors in information systems may have noticed that entry-level textbooks and other course materials portray information systems as part of organizational rationality. Some simple concepts emphasizing the human element relative to systems may be introduced. Advanced courses may explain difficulties with this portrayal and suggest that simple, rationality-based methods for doing systems analysis and design may be deficient. Other fields have somewhat the same problem. Elementary accounting presents accounting processes, reports, and concepts in a very rational context of measurement of the financial consequences of organization activities. Intermediate accounting explains that the elementary accounting presentations did not deal with difficult measurement and reporting problems.

One can argue that a rational, orderly presentation of the structure and purpose of the information system of an organization helps students to develop a useful mental model 
of the system. Likewise, there are pedagogical reasons for describing systems analysis, development, and implementation as a simple rational, step-by-step process with goals, objectives, and deliverables. However, those students who will become practitioners in information systems should gain a richer view of the complexity of systems and system development processes. The problem may be that we have not agreed on the difference between the descriptive, rationality-based material to be presented in the overview course and the rich explanation required by those doing the work or supervising it. The idea of a first survey course followed by a richer, in-depth advanced course is not well defined.

\section{Definitions of the Field}

Although there is no agreed-upon definition for the field, most definitions converge quite well based on the need for two definitions. One definition is based on the observed system. If an organization describes its information system to an observer, using goaldirected language, the system can be explained in terms of its various elements (technical and human) and in terms of the organizational activities served. An additional definition describes the organization and activities of the information system function. Both definitions are required to define information systems as they exist, since both system and function are required. An additional set of definitions deals with the nature of data, information, and knowledge, because these elements are captured, stored, processed, moved, combined, communicated, and so forth by information systems.

\subsection{Definition of Information System Based on the Observed System}

A system-oriented definition describes the observed system and identifies its boundaries within the structure and operations of organizations. This matches the historical development of information technology within organizations. A simple definition might be that an information system is a system in the organization that delivers information and communication services needed by the organization. This can be expanded to describe the system more fully.

\footnotetext{
The information system or management information system of an organization consists of the information technology infrastructure, application systems, and personnel that employ information technology to deliver information and communications services for transaction processing/operations and administration/ management of an organization. The system utilizes computer and communications hardware and software, manual procedures, and internal and external repositories of data. The systems apply a combination of automation, human actions, and user-machine interaction.
}

This definition is based on observations of the technical and procedural components of information systems in organizations and the structures and activities that make it work. The structure of the information system for an organization consists of the hard- 
ware/software infrastructure, repositories, and two broad classes of application software: transaction processing/operations and administration/management.

- Infrastructure. The information technology infrastructure consists of the computer and communications hardware and software and the repository management software. It provides processing, communications, and storage capabilities required by application software systems and user activities.

- Repositories. The repositories store data required for transactions, operations, analysis, decision making, explanations and justifications, and government/legal requirements. Repositories have varying scopes such as enterprise, parts of the organization (divisions, offices, departments, etc.), groups, and individuals. The stores include data about entities relevant to the organization; text and multimedia stores of analyses, reports, documents, data search results, e-mails, faxes, conversations, etc.; stores of procedures and directions for performing organizational activities including models for analysis and decision making. The repositories are also termed databases, files, data warehouses, knowledge bases, and model bases.

- Transaction processing/operations applications. Transaction processing applications record and process business transactions such as accepting a customer order, placing an order with a vendor, making a payment, and so forth. These applications range from periodic transaction processing to online immediate processing. They include web-based applications that link an organization with its customers and suppliers. Operations applications schedule and direct the operations of the organization as products are produced and distributed and services are scheduled and performed. Transaction processing and operations are increasingly integrated in enterprise systems as a continuous flow from transactions to operations that they initiate.

- Administration/management applications. These applications support clerical and knowledge workers in performing tasks individually and collaboratively. They support management requirements for data, analysis, reports, and feedback for operational control, management control, and strategic planning. Areas of application include decision support systems, executive support systems, knowledge management systems, and online analytical processing.

It is important to the field of information systems to understand and explain the characteristics of the observed systems. The infrastructure, repositories, and two broad classes of application systems - transaction processing/operations, and management/ administration - can be studied in terms of form, function, behavior of personnel using and operating the systems, behavior relative to organization activities, and value added by their use.

The definition of the observed system was developed very early. The pioneers in computing in organizations incorporated all of these ideas in their plans and visions. Early plans included all of the above applications. The ability to deliver these concepts grew over the years, but the ideas were there from the beginning. For example, my own definition of the observed system from the 1974 edition of Management Information 
Systems: Conceptual Foundations, Structure, and Development contained the basic concepts:

[An] integrated, man/machine system for providing information to support the operations, management, and decision-making functions in an organization. The system utilizes computer hardware and software, manual procedures, management and decision models, and a data base.

[Davis 1974, p. 5]

Early methodologies for doing information systems work were based on a technical view with the designer dividing work between technology and humans. However, very early in the development of the field, there was recognition of the importance of understanding the way the users understand the outputs of the system. One illustration of this early development was Professor Börje Langefors, holder of the first chair in Sweden for information processing. His seminal book, Theoretical Analysis of Information Systems, was published in 1966. He distinguished between infological and datalogical work areas. Infological concepts and methods relate to the information to be provided to an organization to meet user needs. Datalogical concepts and methods define the organization of data and technology in order to implement an information system. His infological equation was insightful: $I=i(D, S, t)$.

$\mathrm{I}=$ the information produced by the system

$\mathrm{D}=$ the data made available by system processes

$\mathrm{S}=$ the recipient's prior knowledge and experience (world view)

$\mathrm{t}=$ the time period during which interpretation process occurs

$\mathrm{i}=$ the interpretation process that produces information for a recipient based on both the data and the recipient's prior knowledge and experience

In the infological equation, information is not just the result of algorithmic processing but is also the result of the prior knowledge and experience of the person receiving the results of processing data. Therefore, no two individuals receive the same information from this processing. However, users in common problem domains and similar data uses have prior knowledge and experience that is sufficiently similar to allow shared use of data and meaningful communication of interpretations. One of the important tasks of system developers for structured reporting and analysis applications is to elicit and document shared concepts within a domain of practice. In some cases, change processes are incorporated in system development to ensure that the recipients have a shared knowledge of the concepts and rules underlying the application and a shared understanding of the reports and analyses provided to them.

\subsection{Definition of Information System Function and its Activities}

Organizations are human artifacts designed and built to achieve human organization objectives. Information systems are human artifacts needed by organizations. The needs and requirements must be identified and systems must be planned and built. They are the product of human imagination and human development processes. The requirements 
reflect not only technical capabilities but also social and behavioral considerations. Systems are built through a combination of information technology and development procedures. The system procedures include software, human procedures, and procedures incorporated in forms and other non-technical mechanisms.

The domain of information systems as a function or field of activity and study includes activities for system development and system management and evaluation:

- Strategic planning for information and communication systems. There is a coalignment of the organization strategy with information and communication system strategy. Technology capabilities provide opportunities for the organization strategy, and the organization strategy defines requirements for information technology infrastructure and systems. For example, the capabilities of the Internet provide opportunities for the IS function to suggest new ways of doing business, and the organization's strategic decisions to deploy web-based applications define elements of the information systems strategy.

- Management of the information system function. This includes unique problems of management of IS activities and resulting unique measurement and evaluation issues. Management issues include evaluation of outsourcing for various activities and supervision of outsourcing contracts.

- Information systems personnel. There are unique positions such as systems analyst, programmer, and network designer. Selecting, motivating, training, managing, and evaluating these personnel employ both general human resources methods and unique factors related to information systems employees.

- System development processes. Requirements determination and development processes ranging from structured development cycles to rapid prototyping and end user systems are part of these processes. Unique methods and tools are employed, such as development methodologies, CASE tools, and diagraming notations and processes. Information systems change organizations. They reflect management decisions about how the organization will interact with customers, suppliers, personnel, etc. Implementation of new systems is a change process with significant organizational effects.

- Evaluation. Evaluation of results includes measurement of satisfaction with systems and economic/organizational effects. Understanding both development successes and failures is useful.

\subsection{Data, Information, and Knowledge}

Information systems provide capture, repositories, processing, and communication of data, information, and knowledge. The definitions of these three terms is made difficult because of the lack of precision in everyday conversation and because one person's data may be another person's information (Buckland 1991). However, there is a convergence relative to the meaning of the terms: 
Data consists of representations of events, people, resources, or conditions. The representations can be in a variety of forms, such as numbers, codes, text, graphs, or pictures.

Information is a result of processing data. It provides the recipient with some understanding, insight, conclusion, decision, confirmation, or recommendation. The information may be a report, an analysis, data organized in a meaningful output, a verbal response, a graph, picture, or video.

Knowledge is information organized and processed to convey understanding, experience, accumulated learning, and expertise. It provides the basis for action. Knowledge may be procedural (how to do something), formal (general principles, concepts, and procedures), tacit (expertise from experience that is somewhat hidden), and meta knowledge (knowledge about where knowledge is to be found).

An information system captures data based on information system design decisions. Not everything can be captured, so someone makes a decision. If all needs for data and uses of information were known in advance, the decisions about the data to capture and store would be simple. However, we do not have foreknowledge. Also, there is a cost of capture and storage, so decisions must be made. The tendency is to capture easily measured characteristics of events. For example, in a retail purchase transaction, item number, price, date, etc. are captured, but potentially vital data items are not captured, for example, the mood of the customer, whether the item was the one wanted or purchased as a second choice, whether for own use or a gift, and so forth.

Capturing knowledge has both conceptual and practical problems. The employees of an organization may develop habits and informal procedures that provide high levels of service and performance. The procedural knowledge is not codified and, therefore, not stored by the organization. Tacit knowledge of how to do things is stored in the minds of workers but not in the manuals or training courses of the organization. There is typically no organizational memory for tacit knowledge. Capturing and codifying procedural knowledge and the tacit knowledge of valuable long-term employees is now a major information systems issue.

\section{Approaches to Conceptual Foundations}

The conceptual foundations for a field are the set of concepts and propositions that explain why structures are designed the way they are, tasks are scheduled and accomplished in the way they are, and activities are performed the way they are. For example, maintenance of application systems can be explained by a few underlying concepts, such as:

- Open systems decay over time as the environment changes; therefore, the system no longer fits the altered environment. 
- When users employ an application, they appropriate the technology and alter the way it is used from that envisioned by the developers.

The concepts or propositions employed to explain or guide information systems design and its development processes come from fields that typically have bodies of knowledge related to the concepts or propositions used. These are, therefore, termed underlying disciplines.

For an observer who takes a normative standpoint, information systems is fairly straight forward (as are most applied fields). Organizations have transaction processing and operations requirements and requirements related to administration, management, analysis, and decision making. These require an information technology infrastructure that must implemented and managed. Based on requirements, application systems are either acquired or built. Systems must be designed, maintained, and updated. Training and support must be provided. The observer may conclude the field is simple and its concepts are simple.

In practice, infrastructures and applications are not just technology and software. There is a complex interaction with technology, application software, and users. Requirements are not obtained by simply asking. There is a process of discovery for both users and developers as the requirements emerge. Strategic applications, productivity improvement, reduced cycle time, user friendly systems, quality improvement, and so forth are the result of innovative thinking that comes from dialogue among participants who have trust both in each other and also in the processes of requirements determination and system development. The field is, therefore, complex and its conceptual foundations have emerged from the intersection of information systems problems with principles, concepts, and prescriptions from a number of fields (Davis 1992).

There are three approaches to conceptual foundations and underlying disciplines for an applied academic field. One is to be open to ideas from many other disciplines; any time there is an interesting intersection with concepts in another discipline, the concept and related disciplinary knowledge is added to the set of conceptual foundations. Conceptually, the entire set of useful concepts defines the boundaries of the field as an academic discipline. The second approach is to focus on a core set of conceptual foundations. Other ideas may be appropriated for information systems use, but the core set defines the field as an academic discipline and not the entire set of useful concepts. The intersection approach and the core approaches are at two radically different ends. A third alternative is an evolutionary view that the information systems field will become more bounded as some concepts are dropped as not being useful enough to stay in the set of important concepts.

\subsection{The Underlying/Intersection Approach to Conceptual Foundations}

The conceptual foundations for the emerging field of information systems in organizations started to develop in the 1960s. Scholars in North America and Europe were the most active in the early developments. Early conceptual definitions of information systems (or management information systems) focused on the elements making up the system of information storage and processing and the applications supported by the 
system. The conceptual foundations that emerged were based on the interaction of information technology, information systems, organizational systems, and individuals and groups employing or affected by the systems. The key concepts or underlying conceptual foundations were defined as concepts of information, humans as information processors, system concepts, concepts of organization and management (relevant to information systems), decision making, and value of information. Soft systems and socio-technical concepts were introduced to counter-balance a strong tendency to view information systems from an engineering rationality and not consider the views and perceptions of all stakeholders.

The boundaries of the field of information systems from the mid-1960s to the mid1980 s were characterized by expansion of infrastructure, applications, and conceptual foundations. Infrastructure changes were the combining of communications systems with computing systems and the emergence of end-user computing and personal computers. Applications expanded in support of collaborative work and individual and group decision making. The role of information systems in organizational communications introduced organizational communications as an underlying set of concepts. Databases were conceptualized as repositories of data (attributes) about things (entities) important to the organization and its processes. Organization power and politics considerations emerged as important concepts. Strategic value of information technology began to be studied. Adoption of new technology became an important topic. Some concepts of interorganizational systems were introduced.

From the mid-1980s to the year 2000, reengineering emerged. Although presented as a revolutionary idea, it is based on the fundamental system concept that organizational systems decay (entropy) and should therefore periodically be reengineered, sometimes radically. The radical idea of artificial intelligence achieved some practical results with expert systems, thereby bringing expertise and expert systems into the set of concepts underlying system design. Information systems had been justified on the basis of economic value to the firms adopting them; value to the economy was assumed. Under questioning relative to the economic value of information technology in improving productivity, analytical modeling and economic analysis emerged as a part of the information systems field. As the percentage of knowledge workers increased, concepts began to emerge about how knowledge work quality and productivity are improved by information technology. Recognition that information technology had the power to remove time and location constraints to organizations focused attention on the value of knowledge resources in an organization, leading to knowledge management as a subarea in the field. The Internet and the technology for the world wide web changed the nature of information storage, search, and access. Web technology changed both business to business and business to consumer applications. Search strategies and knowledge acquisition (long reserved for librarians and similar experts) became part of the field of information systems.

The intersection approach looks for concepts and principles from other fields that may apply to problems in the information systems field. One of the most important reasons to keep the intersection approach is that more powerful ideas and innovations are likely to arise at the intersection of two fields. The thinking of information systems personnel can be enriched by encouraging exploration in other fields rather than looking inward to the body of knowledge accepted by the IS field. 


\subsection{The "Core" Approach to Conceptual Foundations}

An objection to the observed system and information system function as the basis for defining the field and its research boundaries is that the definition is not stable. As a new technology or new area of application emerges, it is pasted onto the definition of the observed system and the functional activities. To illustrate, mobile communication/ computing devices and electronic commerce are examples of new technology and new applications. Both appear to be important to observed systems, and both have an effect on the activities of the IS function. The new systems lead to new sets of concepts and related disciplinary knowledge, partly because there is no set of core concepts that can be applied to all new technologies and new application areas. There is no way to constrain the growth of concepts borrowed from other discipline.

With unconstrained growth in intersections, a field may become unfocused. If there were agreement on core concepts, they might better define the information systems discipline within the context of other organization disciplines. The core concepts explain why information systems as a field differs from other fields. Also, core concepts can be the basis for cumulative research that is not constrained by the changing landscape of technology innovations and new applications.

Weber (1997; see also Wand and Weber 1995) argues that deep structure information systems phenomena are the core of information systems as an academic discipline. The deep structure of the information system consists of those characteristics of the information system that capture the meaning of the real-world system as perceived by users. An information system is a system that represents objects and activities in the real world. It codes, stores, receives and transmits, and processes representations of the real world. It also should be able to track events in the system it represents. The representation should communicate the structure of the system in terms of its behavior, including subsystems that make it easier for users to understand the system and deal with it. The representation should be simpler and more efficient for communication and reasoning than the system being described. Weber argues that developing a better understanding of the core phenomena will provide a conceptual foundation for how well an information system represents user perceptions of the real-world system. To clearly explain the deep structure will provide a unique information system contribution to theory.

A core serves to characterize the discipline. It represents the essence of the discipline - the body of knowledge that leads others to recognize it and to acknowledge it as being distinct from other disciplines and not just a pale imitation of them....I can see only three ways in which the core of a discipline can be teased out. The first is to identify a body of phenomenon that is not accounted for by theories from other disciplines and to build novel theories to account for these phenomena.... The second way is to take phenomena that are purportedly accounted for by theories from other disciplines and to again build novel theories to account for these phenomena.... The third way is to look for breakdowns in theories borrowed from reference disciplines when they are applied to IS-related phenomena. [Weber 1997, pp. 27-28, emphasis in original.] 
The core approach positions the information systems function as principal providers of information technology infrastructure, application systems and information technology services. This suggests a stronger emphasis on system principles (both hard and soft), matching technology infrastructure to organization structure, technology implementation and system change management, stability and quality in system operations, information technology strategy planning, and evaluation of value added. Under this core view, IS is not the principal mover for web-based applications, e-commerce, knowledge management, etc. but is the development partner with others in the organization.

Falkenberg and Lindgreen (1989) take a different approach to information system concepts. They tend to focus on conceptual models, axioms, taxonomies, levels of abstraction, etc. This effort fits into the core approach. A subsequent effort by Falkenberg et al. (1996) produced a framework for information systems concepts as part of the FRISCO Task Group of IFIP. This group continues to meet and hold conferences on information system concepts.

\subsection{The Evolutionary Approach to Reducing the Set of Conceptual Foundations}

Without deciding on the question of whether there should be tighter boundaries around the concepts and theories dealt with by information systems, there are natural evolutionary tendencies toward tighter boundaries. Given the large number of interesting concepts related to information systems (along with an underlying body of knowledge), there is a natural tendency to constrain the field in order to be more coherent, focus on the key elements, etc. The second evolutionary tendency for reducing the set of conceptual foundations comes from the fact that some interesting ideas, concepts, theories, and practices are discarded from the set of conceptual foundations because they are not useful enough to continue in use or to continue research based on them.

The stream of research described as cognitive style is an example of dropping a topic that had consumed significant resources in the IS field. The basic proposition is that people differ in their cognitive abilities and information systems should be designed to match them. A good system design/cognitive ability match presumably results in improved performance. There is a significant body of knowledge about cognitive styles. Three problems with the cognitive matching proposition finally lead to the demise of this research.

1. People are not either/or relative to cognitive style; there is a distribution. For example, heuristic and analytic styles range from highly one or the other to slightly more one than the other. There is no method for calibrating information system design to match the variety of cognitive styles.

2. People are adaptable. They can adapt to systems that are not designed explicitly to their intuitive style. Training will help people adapt the system to their natural cognitive style. A person with a heuristic style can adapt to a system designed for an analytical style. 
3. Very few applications are designed for a single person. Not only is it costly, but an individual may move to another position and the next person, with perhaps another style, will need to use the system. Training the new user is generally less costly than creating a new system. Also, applications may be used by group, so the system needs to be useable by all members of the group.

\section{The Current and Possible Future Status of Conceptual Foundations for Information Systems}

Looking at the academic field of information systems in the year 2000, its scope in terms of technology, development processes, and applications has expanded dramatically in the past 30 plus years. This expansion covers the time when information systems emerged as an academic field (in the mid-1960s) to the present. The scope is so large in the year 2000 that subfields have begun to emerge.

As a check against my observations of conceptual foundations and topics in the field, I reviewed articles in the completed research and research in progress for ICIS 1998 and ICIS 1999 and articles in eight issues of the MIS Quarterly from December 1997 through September 1999. The underlying bodies of concepts and methods for the articles having a declared or implied concept/theory were as follows:

\begin{tabular}{|l|c|}
\hline Underlying Bodies of Concepts and Theories & $\begin{array}{c}\text { Number of } \\
\text { Uses }\end{array}$ \\
\hline Psychology & 5 \\
Cognitive Psychology & 17 \\
Sociology/Organization Behavior & 49 \\
Management Strategy & 19 \\
Economics & 20 \\
System Concepts and Principles & 4 \\
Communications & 2 \\
Decision Making & 6 \\
Information Concepts & 2 \\
& \\
\end{tabular}

I also tallied the articles in terms of concepts, theories, processes, and applications systems that are unique or somewhat unique to information and communications systems in organizations: 


\begin{tabular}{|l|c|}
\hline $\begin{array}{c}\text { Bodies of Concepts, Theories, Processes, and } \\
\text { Application Systems Unique or Somewhat } \\
\text { Unique to IS }\end{array}$ & $\begin{array}{c}\text { Number of } \\
\text { Uses }\end{array}$ \\
\hline Information systems management processes & 15 \\
Information system development processes & 30 \\
Information system development concepts & 20 \\
Representations in information/communication & 8 \\
systems (databases, knowledge bases, etc.) & 59 \\
Application systems (somewhat unique because \\
of information technology)
\end{tabular}

These illustrate the use of underlying disciplines but do not disclose the variety of concepts and theories from these disciplines or the variety of unique IS processes and applications. An expanded view for underlying disciplines and unique IS processes and applications is found in Tables 1 and 2. These are extensive but may not include all concepts, theories, processes, and applications that are part of the field.

\subsection{Information Systems Conceptual Foundations in the Future}

There are three possibilities in the next decade or so relative to conceptual foundations for the academic field of information systems:

- A continued expansion of conceptual foundations as more intersections develop with other disciplines. The interesting problems and issues for a field such as information systems are at the intersection with other disciplines and bodies of knowledge. As examples, group decision systems can be better implemented based on research that considers underlying research on group decision processes. Information technology systems for knowledge management are improved and IS research on knowledge management is more insightful when research in cognitive science is incorporated. Consumer psychology research becomes important when researching e-commerce systems. Under this scenario, each new area of application of information systems in organizations may bring with it underlying concepts and a body of research, so there will be continued expansion of conceptual foundations.

- A dramatic redrawing of the map of conceptual foundations to emphasize the core. Given the pressure from academic colleagues to define a core for information systems and proposals for this core from respected IS colleagues, the field might decide to define the field in terms of conceptual foundations at the core. Many fields in the university have done this. They define their field narrowly in terms of core activities and unique contributions. They exclude many interesting intersections with other fields. 


\section{Table 1. Underlying Disciplines for Information Systems and Concepts/Theories Used}

Psychology

Theories of human behavior

Motivation theories

Theory of reasoned action

Cognitive Psychology

Human information processing

Human cognition

Expertise

Artificial intelligence

Cognitive style

Creativity

Knowledge

Cognitive representations/ visualization

Human-machine interfaces

Sociology/Organization Behavior

Nature of work (knowledge work, clerical work, etc.)

Governance theories

Organization design concepts

Process models

Culture

Technology Adoption/Diffusion

Adaptive structuration

Social network theory

Actor network theory

Social influence

Organization change

Organization learning

Trust

Ethics

Management/Strategy

Strategy

Innovation

Competitive advantage

Resource view of firm

Knowledge management

Risk management

Evaluation

Outsourcing
Economics

Principal-agent theory

Transaction cost economics

Productivity

Information economics

Social welfare

Adverse selection

Value of information

Incomplete contracting

Intermediation

System Concepts and Principles

Artificial systems

Requisite variety

Soft systems

Complexity

Control theory-cybernetics

Socio-cybernetic theory of acts

Task/technology fit (equifinality)

System economics (reuse)

Maintenance of systems (negative entropy)

Process theory

System models

Communications

Media choice

Collaborative work

Speech acts theory

Decision making

Behavioral decision making

Normative decision models

Group decision making

Neural networks/genetic algorithms

Information concepts

Mathematical theory of communications

Quality, errors, and bias concepts

Value of information

Semantics

Semiotics (theory of signs) 


\section{Table 2. Bodies of Concepts, Theories, Processes, and Applications Unique or Somewhat Unique to Information Systems}

Information systems management processes

Strategic planning for infrastructure and applications

Evaluation of IS/IT in the organization

Management of IS personnel

Management of IS function and operations

Information system development processes

IS project management

IS project risk management

Organization/participation in projects

Requirements-technical and social

Acquisition of applications

Implementation of systems

Training/acceptance/use

Information system development concepts

Concepts for methods

Socio-technical concepts

Speech acts theory

Rational decomposition concepts for requirements

Social construction for requirements

Concepts of errors and error detection

Testing concepts for complex sociotechnical systems

Quality concepts for information/ communications systems
Representations in information/communication systems (databases, knowledge bases, etc.)

Representations of the "real" world

Coding of representations

Storage, retrieval, and transmission of representations

Tracking events

Representing changes in events

Representing structure of system

Applications systems (examples)

Knowledge management

Expert systems

Neural networks

Decision support systems

Collaborative work systems/virtual teams

Group decision support systems

Telecommuting systems/distributed work

Supply chain systems

ERP systems

Inter-organizational systems

Organization communications systems: internet, intranet, e-mail, etc.

Training systems

E-commerce applications

Customer support systems

- Narrowing of focus with more emphasis on the core, but still including important intersections with other fields. A redrawing of the map of conceptual foundations can define a core but still include bodies of knowledge that clearly underlie information systems. There can be a recognition that the core can incorporate clearly understood concepts without reference to other disciplines that may also use the same concepts.

My view is that the current set of concepts is too large, because some of them are not robust in providing explanations. There needs to be some pruning. The field has tended to ignore some of the core concepts and issues in favor of proven concepts from other disciplines. It will be profitable to remedy this neglect and strengthen the core concepts both by research and by explicating the concepts and their applicability. However, the field of information systems has natural overlap with other disciplines, and these intersections should remain part of the domain of the information systems discipline. 
This evolutionary view of the field can be implemented if leaders in the field identify unprofitable concepts that can be dropped, strengthen the core concepts, and remain open to new intersections if there is good evidence to support their inclusion.

\subsection{Some Comments about Research Methods in Information Systems}

Much of the discussion about the field has contrasted views that Checkland and Holwell (1998) have termed functionalist (hard) versus interpretive (soft). The functionalist, hard system view tends to focus on the goals of organizations and how information systems should be designed to support these rational goals. The interpretive, soft systems view of organizations is multi-faceted with conflict and social relationships dominating. In the functionalist view, information systems are designed to aid rationalized activities and rational decision making. In the interpretive view, information systems provide data and communication facilities used by organization participants in making sense of the world and negotiating actions to be taken. Checkland and Holwell present these two views as opposing and leading to confusion and lack of coherence and stability in an emerging field.

My own experience is that information systems as a field is ahead rather than behind other fields in management and administration. Because information systems began fairly early to become an international discipline, a variety of views about the field and its research were encouraged. The field has a richer set of views than other fields because the positivist philosophy that dominated the American research and the phenomenology philosophy that tended to dominate in Europe were both supported by the worldwide community. The IFIP 8.2 Manchester working conference demonstrated the willingness of researchers in the IS field to appreciate the different approaches to research (Mumford et al. 1985). The MIS Quarterly, which began with an espoused policy of positivist research, demonstrated in practice a willingness to accept interpretive research. The current Editor-in-Chief, Allen Lee, of the MIS Quarterly is known as an advocate of qualitative methods.

In other words, the confusion often cited by those examining the state of the field can be interpreted as a coming together of world views and research views. The field seems to value diversity of methods. To some, the lack of a sparse set of methods and a restricted, accepted vocabulary demonstrates an immature field. I make the counter argument that they demonstrate a field that is incorporating a rich set of methods and vocabulary to make sense of a complicated world. There is a clear trend to an acceptance of positivist and interpretive methods as being complementary. Other fields such as accounting, finance, and marketing are less international and less open to a variety of research methods and world views.

I have often been characterized as a positivist. Actually, my world view of research was altered by the IFIP 8.2 Manchester conference. I believe a world-class scholar must be competent in both hypothesis testing using quantitative data and qualitative, interpretive methods using observations, interviews, and participation. My preference for a hypothesis testing dissertation for entry-level students is pragmatic rather than dogmatic. Such dissertations tend to be more tractable and provide good grounding in data analysis. A student should also have doctoral studies experience in qualitative research. The point is that the best scholars in the field will have an ability to employ both methods. I observe the European doctoral students becoming better trained in 
hypothesis testing methods and American students receiving some training in interpretive methods. There is a coming together rather than a splintering apart.

As a check against my observations of diversity in research methods, I tallied research methods for articles in the completed research and research in progress for ICIS 1998 and ICIS 1999 and articles in eight issues of the MIS Quarterly from December 1997 through September 1999.

\begin{tabular}{|l|l|l|}
\hline Research Method & $\#$ & $\%$ \\
\hline Survey & 37 & 26 \\
\hline Case/cases & 34 & 24 \\
\hline Model without data & 15 & 11 \\
\hline Model with data & 14 & 10 \\
\hline Experiments & 14 & 10 \\
\hline Design/prototype & 12 & 09 \\
\hline Framework & 06 & 04 \\
\hline Other & 08 & 06 \\
\hline
\end{tabular}

\section{Summary and Conclusions}

The essence of the paper is that information systems intersects with many other disciplines. Some view this dependence with alarm. I view it as an opportunity. I agree with Banville and Landry (1992), who state:

The field is attractive to many, including the authors, because of its great variety of approaches and their potential and actual crossfertilization....Members of the MIS field should not refuse any help from other disciplines, given the richness and complexity of their main research object-management information systems-and their numerous facets.

Definitions of the information systems field and IS function tend to converge because practice can be observed and described. The main issue for conceptual foundations in the next decade is whether to focus on a narrow core set of concepts or to continue in the current free market for concepts that are useful and meaningful. Some critical events in the past years suggest that some concepts and related bodies of knowledge will be discarded as not being sufficiently useful and others will be added. We have probably neglected the core and, therefore, it may be useful to define it more clearly and precisely. This effort, however, will not preclude the inclusion of a rich set of intersections with other disciplines. 


\section{References}

Banville, C., and Landry, M. "Can the Field of MIS be Disciplined?," in Information Systems Research: Issues, Methods and Practical Guidelines, R. Galliers (ed.). London: Blackwell Scientific Publishers, 1992, pp. 61-88.

Buckland, M. Information and Information Systems, New York: Praeger Publishers, 1991.

Boland, R. J., Jr., and Hirschheim, R. A. (eds.). Critical Issues in Information Systems Research. Chichester, UK: John Wiley \& Sons, 1987.

Checkland, P., and Holwell, S. Information, Systems and Information Systems-Making Sense of the Field. Chichester, UK: John Wiley \& Sons, 1998.

Cotterman, W. W., and Senn, J. A. (eds.). Challenges and Strategies for Research in Systems Development. Chichester, UK: John Wiley \& Sons, 1992.

Davis, G. B. "Systems Analysis and Design: A Research Strategy Macro-analysis," in Challenges and Strategies for Research in Systems Development, W. W. Cotterman and J. A. Senn (eds.). Chichester, UK: John Wiley \& Sons, 1992, pp. 9-21.

Davis, G. B. Management Information Systems: Conceptual Foundations, Structure and Development. New York: McGraw-Hill Book Company, 1974.

Falkenberg, E. D., Hesse, W., Lindgreen, P., Nilsson, B. E., Oei, J. L. H., Rolland, C. Stamper, R. K., Van Assche, F. J. M., Verrijn-Stuart, A. A., and Kos, K. FRISCO: A Framework of Information Systems Concepts. The IFIP WG 8.1 Task Group FRISCO, December 1996. Available from http://ftp.leidenuniv.nl/pub/rul/fri-full.zip.

Falkenberg, E. D., and Lindgreen, P. (eds.). Information System Concepts: An In-depth Analysis. Amsterdam: North Holland, 1989.

Langefors, B. Theoretical Analysis of Information Systems. Lund, Sweden: Studentlitteratur, 1966.

Mumford, E., Hirschheim, R. A., Fitzgerald, G., and Wood-Harper, A. T. (eds.). Research Methods in Information Systems. Amsterdam: North-Holland, 1985.

Nissen, H.-E., Klein, H. K., and Hirschheim, R. (eds.). Information Systems Research: Contemporary Approaches and Emergent Traditions. Amsterdam: North-Holland, 1991.

Nurminen, M. I. People or Computers: Three Ways of Looking at Information Systems. Lund, Sweden: Studentlitteratur, 1988.

Wand, Y., and Weber, R. "On the Deep Structure of Information Systems," Information Systems Journal (5), July 1995, pp. 203-223.

Weber, R. Ontological Foundations of Information Systems. Melbourne, Australia: Coopers \& Lybrand, 1997.

\section{About the Author}

Gordon B. Davis is the Honeywell Professor of Management Information Systems at the Carlson School of Management, University of Minnesota. He received his MBA and $\mathrm{Ph}$.D. from Stanford University. He also holds honorary doctorates from the University of Lyon, the University of Zurich, and the Stockholm School of Economics. He is a Fellow of the Association for Computing Machinery. He is the U.S.A. representative of IFIP Technical Committee 8 (Information Systems) and has served as chairman of TC8. He serves on the editorial boards of major journals in the field. He has published extensively and written 20 books in the MIS area. His areas of research include MIS planning, information requirements determination, conceptual foundations for IS, control and audit of information systems, quality control for user-developed systems, in-context assessment of information systems, and management of knowledge work. Gordon can be reached by e-mail at gdavis@csom.umn.edu. 